\title{
Bronchoscopic administration of bovine natural surfactant in ARDS and septic shock: impact on gas exchange and haemodynamics
}

\author{
D. Walmrath*, F. Grimminger*, D. Pappert", C. Knothe ${ }^{\star}$, U. Obertacke ${ }^{+}$, A. Benzing ${ }^{\S}$, \\ A. Günther*, T. Schmehl*, H. Leuchte*, W. Seeger*
}

Bronchoscopic administration of bovine natural surfactant in ARDS and septic shock: impact on gas exchange and haemodynamics. D. Walmrath, F. Grimminger, D. Pappert, C. Knothe, U. Obertacke, A. Benzing, A. Günther, T. Schmehl, H. Leuchte, W. Seeger. (C) ERS Journals Ltd 2002.

ABSTRACT: The aim of the present study was to investigate the feasibility and efficacy of bronchoscopic surfactant administration in a noncontrolled multicentre study in five university centres.

A total number of 27 patients, suffering from severe acute respiratory distress syndrome (mean \pm SEM lung injury score: $3.15 \pm 0.06$ ) and septic shock (Acute Physiology and Chronic Health Evaluation (APACHE) II score at study entry 33.2 \pm 1.3 , lactate $4.3 \pm 0.6 \mathrm{mmol} \cdot \mathrm{L}^{-1}$ ) were studied. The patients were ventilated with a mean tidal volume of $11.0 \pm 0.5 \mathrm{~mL} \cdot \mathrm{kg}^{-1}$ body weight (bw), either volume or pressure controlled, with $16.3 \pm 2.8 \mathrm{cmH}_{2} \mathrm{O}$ positive end-expiratory pressure, for an average of $3.5 \pm 0.3$ days at study entry. A natural bovine surfactant extract $\left(300 \mathrm{mg} \cdot \mathrm{kg}^{-1}\right.$ bw Alveofact $(\mathrm{B}$; mean total volume $378 \mathrm{~mL}$ ) was delivered in divided doses to each segment of the lungs via flexible bronchoscope within $\sim 45 \mathrm{~min}$.

No untoward effects on gas exchange, lung mechanics and haemodynamics were noted during the procedure of surfactant administration. Within $12 \mathrm{~h}$ the oxygen tension in arterial blood/inspiratory oxygen fraction increased from a mean of $109 \pm 8 \mathrm{mmHg}$ to $210 \pm 20 \mathrm{mmHg}(\mathrm{p}<0.001)$. In seven patients, in whom gas exchange again deteriorated with further progression of the disease, a second surfactant dose of $200 \mathrm{mg} \cdot \mathrm{kg}^{-1}$ was administered $18-24 \mathrm{~h}$ after the first application, again improving arterial oxygenation. A total of 15 patients survived the 28-day study period (mortality rate $44.4 \%$, compared to a calculated risk of death for the given APACHE II scores of $74.0 \pm 3.5 \%$ ), with all causes of death being nonrespiratory. The bronchoscopic application of a high dose of natural surfactant in patients with severe acute respiratory distress syndrome and septic shock is both feasible and safe, resulting in a pronounced improvement in gas exchange.

Eur Respir J 2002; 19: 805-810.

\begin{abstract}
*Dept of Internal Medicine II, "Dept of Anesthesiology and Intensive Care Medicine, Justus-Liebig-University, Giessen, Germany; ${ }^{*}$ Dept of Anesthesiology and Intensive Care Medicine, Klinikum Rudolf Virchow, Berlin, Germany; ${ }^{+}$Dept of Trauma Surgery, University of Essen, Germany; ${ }^{\circledR}$ Dept of Anesthesiology, Albert-LudwigsUniversity, Freiburg, Germany.
\end{abstract}

Correspondence: W. Seeger, Dept of Internal Medicine, Justus-Liebig University Giessen, Klinikstrasse 36, D-35392 Giessen, Germany.

Fax: 496419942359

E-mail: Werner.Seeger@innere.med. uni-giessen.de

Keywords: Acute respiratory distress syndrome

gas exchange

septic shock

surfactant administration

Received: May 92001

Accepted after revision January 92002

This study was supported by the Deutsche Forschungsgemeinschaft.
Surfactant replacement therapy has unequivocally been shown to improve morbidity and mortality in neonatal respiratory distress syndrome [1], a disease characterized by a primary lack of alveolar surfaceactive material. In adults suffering from an acute respiratory distress syndrome (ARDS), severe surfactant abnormalities are similarly encountered, however, the underlying pathogenetic mechanisms are much more complex [2-6]. Changes include marked alterations in the surfactant phospholipid composition, loss of the surface-active large surfactant aggregate fraction and its surfactant protein (SP)-B and SP-A content as well as inhibition of surfactant function by leaked plasma proteins, oxygen radicals and proteases in the alveolar compartment. Several studies in experimental ARDS models have nevertheless documented the efficacy of endobronchial surfactant administration, provided the surfactant inhibitory mechanisms are supervened by a sufficiently large quantity of surface-active material delivered to the alveolar space $[7,8]$.
Concerning ARDS patients, however, controversy as to the feasibility and efficacy of endobronchial surfactant replacement still exists, with only a limited number of studies currently being available. When administering $50 \mathrm{mg} \cdot \mathrm{kg}^{-1}$ body weight (bw) of a porcine natural surfactant preparation (Curosurf; Chiesi Farmaceutici, Parma, Italy) in severe ARDS, SPRAGG et al. [9] did not observe any adverse effects, but noted that there was only limited improvement in gas exchange. On administering $8 \times 50 \mathrm{mg} \cdot \mathrm{kg}^{-1}$, $4 \times 100 \mathrm{mg} \cdot \mathrm{kg}^{-1}$ or $8 \times 100 \mathrm{mg} \cdot \mathrm{kg}^{-1}$ bw of a bovine surfactant preparation [10] via an endotracheal tube, GREGORY et al. [10] reported a significantly improved arterial oxygenation in the $4 \times 100 \mathrm{mg} \cdot \mathrm{kg}^{-1}$ group, they also noted a reduced mortality as compared to the nontreated controls. The present study group, reported rapid and sustained improvement in arterial oxygenation, in a small number of patients $(n=10)$, suffering from septic ARDS, in whom a mean of $400 \mathrm{mg} \cdot \mathrm{kg}^{-1}$ bw of a natural bovine surfactant product (Alveofact $\mathbb{R}$; Thomae $\mathrm{GmbH}$, Biberach, 
Germany), was delivered in divided doses to each segment of the lung via a bronchoscopic technique [11]. In contrast, AnZueto et al. [12] did not observe any effect on gas exchange and mortality when administering a synthetic surfactant material (Exosurf) via an aerosol technique to the airspaces of patients with sepsis-induced ARDS (5 days continuous aerosolization; total deposited doses estimated to be $\sim 5 \mathrm{mg} \cdot \mathrm{kg}$ $\mathrm{bw}^{-1} \cdot \mathrm{day}^{-1}$ ) [12]. Finally, WiLLSON et al. [13] recently reported a rapid improvement in arterial oxygenation, earlier extubation and decreased stay at the paediatric intensive care unit after tracheal instillation of $2800 \mathrm{mg} \cdot \mathrm{m}^{-2}$ of a calf surfactant extract (Infasurf) in children aged between 1 month-18 yrs, suffering from ARDS.

The results of a multicentre noncontrolled study, investigating the effects of bronchoscopic administration of $300-500 \mathrm{mg} \cdot \mathrm{kg}^{-1}$ bw natural bovine surfactant extract in a total of 27 patients suffering from severe ARDS and septic shock are presented here. The first 10 patients in this study were included in a previously reported communication [11]. The investigation was intended and designed to be a pilot study for determining the efficacy and safety of bronchoscopic surfactant delivery in these severely ill patients. In particular the authors asked the patients whether: 1) the overall procedure of prolonged bronchoscopy and segmental delivery of a large amount of surfactant provoked adverse effects on gas exchange and haemodynamics, and 2) whether this approach resulted in a significant improvement in the arterial oxygenation. In addition, bronchoalveolar lavages pre- and postsurfactant administration were performed for direct investigation of the impact of this procedure on the biophysical and biochemical properties of the alveolar surfactant system in the diseased patients. This data is reported in the accompanying paper [14].

\section{Methods}

The study was performed in five university centres between 1994-1996, which enrolled " $n$ " patients: Berlin University/Anaesthesiology $(n=4)$; Essen University/Surgery $(n=1)$; Freiburg University/Anaesthesiology $(\mathrm{n}=1)$; Gießen University/Anaesthesiology $(n=2)$; Gießen University/Internal Medicine $(n=19)$. The institutional ethics committee at each centre approved the study protocol. Each patient or their next of kin/legal guardian gave informed consent before study entry.

Patients were considered for study entry if they were aged between 18-70 yrs, had developed acute respiratory failure with typical bilateral infiltrates on the chest radiograph after a typical predisposing event (sepsis, trauma, witnessed aspiration, multiple transfusion), had a Murray score $\geqslant 2.5$ [15], and had been ventilated for no longer than $96 \mathrm{~h}$ since ARDS diagnosis. All criteria had to be fulfilled over a baseline period of $12 \mathrm{~h}$ preceding study entry. The following exclusion criteria were checked in all patients: pregnancy, acute myocardial infarction, left heart failure (pulmonary capillary wedge pressure
$>18 \mathrm{mmHg}$ as assessed by a pulmonary-artery catheter), lung contusion, pre-existing pulmonary diseases (fibrosis, chronic obstructive lung disease), malignant underlying disease, immunosuppressive drugs and leukopenia (white blood cells $<1000 \cdot \mu \mathrm{L}^{-1}$ ), severe traumatic or hypoxic brain injury, additional investigational drugs.

The patients were ventilated with a tidal volume (mean \pm SEM) of $11.0 \pm 0.5 \mathrm{~mL} \cdot \mathrm{kg}^{-1} \mathrm{bw}$, a positive endexpiratory pressure (PEEP; including "auto-PEEP" when using inverse-ratio ventilation) of $16.3 \pm$ $2.8 \mathrm{cmH}_{2} \mathrm{O}$ and a peak inspiratory pressure of $37.4 \pm$ $1.0 \mathrm{cmH}_{2} \mathrm{O}$. Both volume-controlled and pressurecontrolled ventilatory modes were applied. The mean oxygen tension in arterial blood/inspiratory oxygen fraction $\left(\mathrm{Pa}, \mathrm{O}_{2} / \mathrm{Fi}_{1} \mathrm{O}_{2}\right)$ value of the 27 patients at study entry under these ventilatory conditions was $109 \pm 8 \mathrm{mmHg}$. At the time of enrolment, all patients suffered from septic shock according to the definition of Bone et al. [16]. All patients required vasopressor therapy in spite of adequate volume loading, the mean systemic resistance was $642 \pm 31 \mathrm{dyn} \cdot \mathrm{s}^{-1} \cdot \mathrm{cm}^{-5}$, the mean lactate level was $4.3 \pm 0.6 \mathrm{mmol} \cdot \mathrm{L}^{-1}$ and the Acute Physiology and Chronic Health Evaluation (APACHE) II score was $33.2 \pm 1.3$. Thirteen patients suffered from additional acute renal failure, demanding treatment with haemofiltration or haemodialysis. Clinical monitoring included a thermodilution pulmonary artery and a femoral or radial artery catheter. Bronchoalveolar lavage (BAL) was performed $3 \mathrm{~h}$ prior to the first and 15-18 and $72 \mathrm{~h}$ after the first surfactant administration; techniques of the lavage procedure have been described previously [11].

The baseline evaluation before treatment consisted of taking a medical history and physical examination, standard haematological and blood-chemistry measurements, urine analysis, 12-lead electrocardiogram, chest radiography as well as measurements of haemodynamics (table 1), gas exchange and ventilatory parameters. Repetitive analysis of haemodynamics and gas exchange was performed as indicated in table 1 and figure 1 . Chest radiographs were obtained at days $0-4,7,10,14,21$, and 28. During the 28-day study period, all deaths and adverse events, drug related or not, were reported.

After a stable baseline period of $6 \mathrm{~h}$, time was set at zero and $300 \mathrm{mg} \cdot \mathrm{kg}^{-1}$ bw of bovine surfactant (Alveofact $($ ) ) was bronchoscopically delivered in divided doses to each segment of the right and left lung (total amount of surfactant $22.7 \pm 3.4 \mathrm{~g}$ in $\sim 378 \mathrm{~mL}$ saline). Starting from the lower segments, the bronchoscope was wedged in each single segment for injection of the aliquot, followed by 1-2 min maintenance of the wedge position to avoid a major reflux of the surfactant material into the central airways. The overall treatment procedure lasted $45 \pm 11 \mathrm{~min}$. During the period of surfactant administration, the supine position of the patient and the ventilator settings were not changed. In those patients in whom the bronchoscopic surfactant administration caused an improvement in the $P \mathrm{a}, \mathrm{O}_{2} / \mathrm{Fi}_{1} \mathrm{O}_{2}$ of $\leqslant 25 \%$, which was however, lost again over the next $18-24 \mathrm{~h}$, retreatment with an additional surfactant dose of $200 \mathrm{mg} \cdot \mathrm{kg}^{-1} \mathrm{bw}$ was allowed $18-24 \mathrm{~h}$ after the first 
Table 1. - Haemodynamic variables before and $\leqslant 72 \mathrm{~h}$ after surfactant administration

\begin{tabular}{|c|c|c|c|c|c|c|}
\hline & \multicolumn{6}{|c|}{ Time point $h$} \\
\hline & 0 & 1 & 12 & 24 & 48 & 72 \\
\hline Heart rate $\min ^{-1}$ & $112 \pm 4$ & $121 \pm 4$ & $112 \pm 4$ & $110 \pm 4$ & $109 \pm 4$ & $110 \pm 4$ \\
\hline $\mathrm{CO} \mathrm{m^{-1 }}$ & $8.5 \pm 0.4$ & $9.2 \pm 0.5$ & $8.5 \pm 0.4$ & $9.2 \pm 0.5$ & $9.0 \pm 0.5$ & $10.3 \pm 0.9$ \\
\hline CVP mmHg & $12.5 \pm 0.9$ & $13.3 \pm 0.9$ & $12.3 \pm 0.9$ & $13.0 \pm 0.9$ & $12.6 \pm 0.8$ & $12.9 \pm 1.1$ \\
\hline PCWP mmHg & $13.9 \pm 0.7$ & $14.6 \pm 0.7$ & $15.1 \pm 0.7$ & $15.6 \pm 0.7$ & $16.2 \pm 0.8$ & $15.3 \pm 1.7$ \\
\hline $\mathrm{SAP} \mathrm{mmHg}$ & $77 \pm 2$ & $75 \pm 2$ & $76 \pm 3$ & $81 \pm 2$ & $78 \pm 2$ & $77 \pm 3$ \\
\hline PAP mmHg & $30 \pm 1$ & $31 \pm 1$ & $32 \pm 1$ & $31 \pm 1$ & $33 \pm 2$ & $31 \pm 2$ \\
\hline SVR dyn $\cdot \mathrm{s} \cdot \mathrm{cm}^{-5}$ & $642 \pm 31$ & $588 \pm 36$ & $633 \pm 34$ & $618 \pm 43$ & $608 \pm 43$ & $632 \pm 125$ \\
\hline PVR dyn $\cdot \mathrm{s} \cdot \mathrm{cm}^{-5}$ & $162 \pm 10$ & $158 \pm 12$ & $163 \pm 11$ & $149 \pm 12$ & $146 \pm 11$ & $152 \pm 22$ \\
\hline
\end{tabular}

Data are presented as mean \pm SEM. CO: cardiac output; CVP: central venous pressure; PCWP: pulmonary capillary wedge pressure; SAP: systemic arterial pressure (mean); PAP: pulmonary artery pressure (mean); SVR: systemic vascular resistance; PVR: pulmonary vascular resistance.

surfactant administration. This was performed in seven out of the 27 patients (total dose $14.0 \pm 0.44 \mathrm{~g}$ in $\sim 230 \mathrm{~mL}$ saline).

All results are presented as mean \pm SEM. Statistical analysis was performed by testing normal distribution first (Kolmogorov-Smirnov test), followed by a pairwise comparison of the pre- and postsurfactant data either by a paired t-test (in cases of normal distribution) or by the Wilcoxon matched-pairs signedranks test.

\section{Results}

A total number of 27 patients (16 male/11 female) with a mean age of $39 \pm 3$ yrs were included in the study. At study entry the mean duration of ventilation was $3.5 \pm 0.3$ days. The bronchoscopic application of

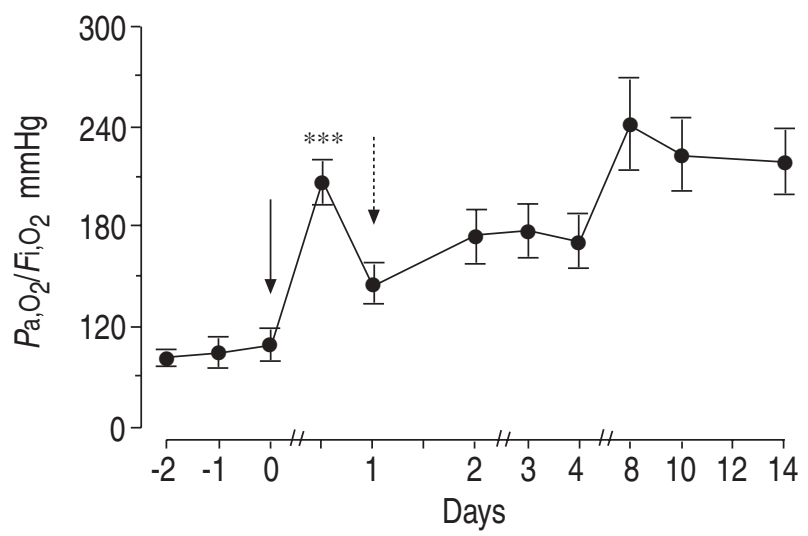

Fig. 1.- Time/course of the oxygenation index (oxygen tension in arterial blood/inspiratory oxygen fraction $\left.\left(\mathrm{Pa}_{\mathrm{a}} \mathrm{O}_{2} / \mathrm{Fi}_{1} \mathrm{O}_{2}\right)\right)$ in response to surfactant application. Means \pm SEM of 27 patients are given. A dose of $300 \mathrm{mg} \cdot \mathrm{kg}^{-1}$ bw natural surfactant (solid arrow) was delivered bronchoscopically in separate doses to each segment of both lungs in all patients (time zero). In seven patients, in whom the surfactant-related increase in arterial oxygenation was partially lost within the next few hours, a second dose of $200 \mathrm{mg} \cdot \mathrm{kg}^{-1}$ bw surfactant (broken arrow) was applied 18-24 h later. The highest $P \mathrm{a}, \mathrm{O}_{2} / \mathrm{Fi}_{\mathrm{i}} \mathrm{O}_{2}$ value is given for each day, and for every $12 \mathrm{~h}$ within the first two days. The number of surviving patients is indicated. Days 2-3: $n=27$; day 4: $n=26$; days $8-10: n=21$; day $14: n=16$. ***: $\mathrm{p}<0.001$ for comparison of the $\mathrm{Pa}_{\mathrm{a}} \mathrm{O}_{2} / \mathrm{F}_{1}, \mathrm{O}_{2}$ values before and after the first surfactant application.
$300 \mathrm{mg} \cdot \mathrm{kg}^{-1}$ bw surfactant increased the $\mathrm{Pa}, \mathrm{O}_{2} / \mathrm{Fi}_{1}, \mathrm{O}_{2}$ from $109 \pm 8$ immediately before onset of administration to $210 \pm 20 \mathrm{mmHg} 12 \mathrm{~h}$ after administration $(\mathrm{p}<0.001$; fig. 1). A total of 14 patients showed an improvement in their oxygenation index of $>25 \%$ of the baseline value within $1 \mathrm{~h}$ and 25 patients within $12 \mathrm{~h}$ after surfactant therapy. The bronchoscopic procedure was well tolerated, no patient displayed a significant drop in arterial oxygenation during surfactant administration. There was no obvious barotrauma within the following $24 \mathrm{~h}$. Haemodynamics, characterized by high cardiac output and low systemic vascular resistance due to septic shock, did not change in any of the patients in response to surfactant administration. The moderately elevated pulmonary vascular resistance did not increase or decrease any further in these patients (table 1).

In seven of the 27 patients, the initial improvement in gas exchange was largely lost over the following 12-18 h. In these patients, a second administration of $200 \mathrm{mg} \cdot \mathrm{kg}^{-1}$ bw surfactant $18-24 \mathrm{~h}$ after the first application again improved the arterial oxygenation: the $\mathrm{Pa}, \mathrm{O}_{2} / F \mathrm{i}, \mathrm{O}_{2}$ increased within $1 \mathrm{~h}$ from $118 \pm 12$ to $155 \pm 30 \mathrm{mmHg}$. The further course of $\mathrm{Pa}, \mathrm{O}_{2} / \mathrm{Fi}_{1} \mathrm{O}_{2}$ of all patients is given in figure 1 . Table 2 gives relevant ventilator variables over the subsequent 28-day observation period.

Fifteen of the 27 patients survived the 28-day study period, and 13 of them were weaned from the ventilator at day 28. The Kaplan-Meier survival curve is given in figure 2 . When analysing the statistical differences between surviving and nonsurviving patients, the following items were identified (table 3): the portion of polymorphonuclear neutrophils in the initial BAL fluid, the APACHE II score and the related risk of death as well as the incidence of renal and liver failure were significantly higher in the nonsurvivors as compared to the survivors. In contrast, the severity of the pretreatment gasexchange abnormalities did not discriminate between those patients who survived and those who died. In the nonsurvivors the cause of death was multi-organ failure and cardiovascular failure due to overwhelming sepsis throughout; none of the patients in this study died from respiratory failure. When calculated for all patients, the APACHE II based risk of death 
Table 2. - Ventilator parameters and gas exchange from baseline $\leqslant 28$ days

\begin{tabular}{|c|c|c|c|c|c|c|c|}
\hline & \multicolumn{7}{|c|}{ Time point } \\
\hline & $0 \mathrm{~h}$ & $24 \mathrm{~h}$ & $72 \mathrm{~h}$ & 7 days & 14 days & 21 days & 28 days \\
\hline Ventilated patients $n$ & 27 & 27 & 27 & 20 & 16 & 9 & 2 \\
\hline$F \mathrm{i}, \mathrm{O}_{2}$ & $0.84 \pm 0.03$ & $0.6 \pm 0.03$ & $0.58 \pm 0.04$ & $0.48 \pm 0.04$ & $0.41 \pm 0.05$ & $0.41 \pm 0.05$ & $0.25 \pm 0.02$ \\
\hline$P \mathrm{a}, \mathrm{CO}_{2} \mathrm{mmHg}$ & $43.9 \pm 8$ & $44.6 \pm 7.6$ & $49.8 \pm 9$ & $45.2 \pm 12.1$ & $42.4 \pm 12.2$ & $42.7 \pm 10$ & $34.5 \pm 4.4$ \\
\hline $\mathrm{PEEP}$ +auto-PEEP $\mathrm{cmH}_{2} \mathrm{O}$ & $16.3 \pm 2.8$ & $15.3 \pm 2.6$ & $14.4 \pm 2.6$ & $11.6 \pm 2.9$ & $7.9 \pm 3.4$ & $8.6 \pm 3.6$ & $9.3 \pm 4$ \\
\hline $\mathrm{PIP} \mathrm{cmH}_{2} \mathrm{O}$ & $37.4 \pm 1$ & $35.5 \pm 1.2$ & $34.7 \pm 1$ & $33.5 \pm 1.7$ & $33.4 \pm 2.4$ & $31.1 \pm 4.6$ & $36.5 \pm 15$ \\
\hline Compliance $\mathrm{mL} \cdot \mathrm{cmH}_{2} \mathrm{O}^{-1}$ & $56 \pm 15$ & $57 \pm 17$ & $54 \pm 21$ & $62 \pm 21$ & $71 \pm 31$ & $74 \pm 35$ & $48 \pm 34$ \\
\hline
\end{tabular}

Data are presented as mean \pm SEM. $F \mathrm{~F}, \mathrm{O}_{2}$ : fraction of inspired oxygen; $\mathrm{Pa}_{\mathrm{a}} \mathrm{CO}_{2}$ : arterial partial pressure of carbon dioxide; PEEP: positive end-expiratory pressure; PIP: peak inspiratory pressure.

was $74 \pm 3.5 \%$, as compared to the actual overall mortality of $44.4 \%$.

\section{Discussion}

The currently employed technique of bronchoscopic administration of a large quantity of surfactant at a volume of almost $400 \mathrm{~mL}$, in divided doses, to each segment of the lung provoked no untoward effects directly attributable to this intervention. Due to the maintenance of the segmental "wedge" position for 1-2 min after the delivery of each aliquot, major flooding of the central airways with surfactant material, which may cause an intermittent increase in airway resistance, was avoided. Accordingly, no substantial increase in inflation pressure (volume-controlled mode) or decrease in tidal volume (pressure-controlled mode) was noted during surfactant administration. There was no decline in arterial oxygenation in any of the patients and similarly, bronchospasm did not occur, which was in accordance with the recent study in surfactant administration in infant ARDS [13]. None of the patients developed new pneumothorax or other signs of barotrauma within $24 \mathrm{~h}$ after surfactant administration. The bronchoscopic technique thus turned out to be feasible and safe in terms of gas exchange and lung mechanics in all the centres involved.

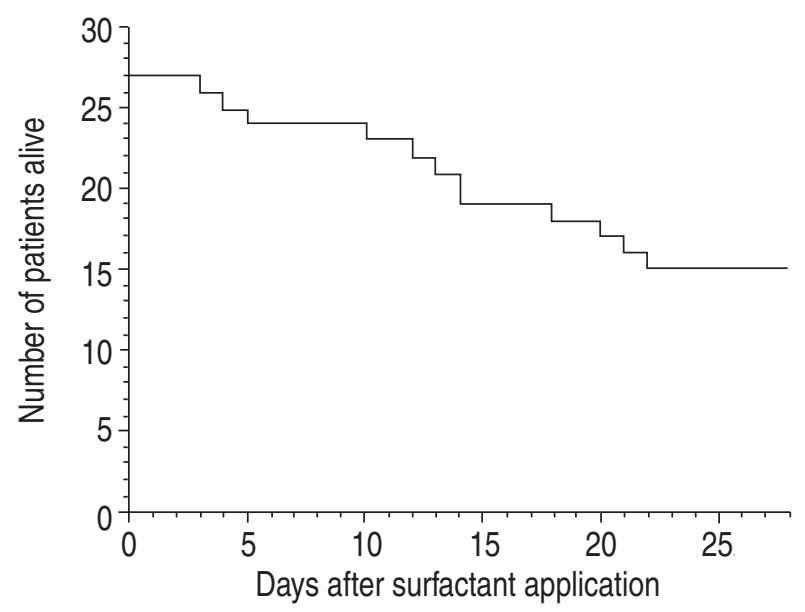

Fig. 2.-Kaplan-Meier curve showing the number of patients surviving over the 28-day study period.
The same conclusion holds true for haemodynamics, which was a critical issue in this study as all patients suffered from septic shock, with markedly decreased systemic vascular resistance in spite of ongoing vasopressor therapy. No change in systemic arterial pressure was noted in response to the bronchoscopic procedure, in association with unchanged cardiac output, right and left ventricular filling pressures and the overall applied dose of vasopressors (data not given in detail). These findings again indirectly indicate the absence of major intrathoracic pressure changes, which would have affected filling pressures, venous return and thereby cardiac output. Interestingly, even the pulmonary vascular resistance did not change, which might have been expected to decrease due to relief of hypoxic pulmonary vasoconstriction in view of improved gas exchange. This finding may thus indicate that the increased pulmonary artery pressure in ARDS is largely attributable to some direct impact of vasoactive inflammatory mediators, not readily influenced by surfactant administration, with less of a contribution from physiological lung vasoregulation.

Table 3. - Characteristics of survivors and nonsurvivors

\begin{tabular}{lccc}
\hline & Death & Survival & p-value \\
\hline Subjects n & 12 & 15 & \\
Age yrs & $41.2 \pm 3.8$ & $37.5 \pm 4.3$ & $\mathrm{NS}$ \\
Initial $P \mathrm{a}_{\mathrm{a}} \mathrm{O}_{2} / F \mathrm{I}, \mathrm{O}_{2}$ & $105 \pm 7$ & $112 \pm 13$ & $\mathrm{NS}$ \\
Responders \% & 92 & 93 & $\mathrm{NS}$ \\
Murray score & $3.3 \pm 0.1$ & $3.1 \pm 0.1$ & $\mathrm{NS}$ \\
Lactate at study & $4.5 \pm 1.5$ & $4.2 \pm 1.2$ & $\mathrm{NS}$ \\
$\quad$ entry mmol $\cdot \mathrm{L}^{-1}$ & & & \\
\% PMN in BALF & $74 \pm 7$ & $50 \pm 8$ & 0.038 \\
APACHE II score & $36.1 \pm 1.1$ & $30.4 \pm 1.6$ & 0.011 \\
Risk of death \% & $85.2 \pm 1.7$ & $70.1 \pm 3.9$ & 0.0025 \\
Days of mechanical & $13.0 \pm 2$ & $17 \pm 2$ & $\mathrm{NS}$ \\
$\quad$ ventilation & & & \\
Multi-organ failure & & & \\
$\quad$ Kidney \% & 75 & 26 & $<0.05$ \\
$\quad$ Kidney and liver \% & 50 & 13 & $<0.05$ \\
\hline
\end{tabular}

Data are presented as mean \pm SEM, unless otherwise stated. $\mathrm{Pa}_{\mathrm{a}} \mathrm{O}_{2} / \mathrm{Fi}_{1} \mathrm{O}_{2}$ : oxygen tension in arterial blood/inspiratory oxygen fraction (oxygenation index); PMN in BALF: polymorphnuclear neutrophils in the bronchoalveolar lavage fluid; APACHE: Acute Physiology and Chronic Health Evaluation; NS: nonsignificant. 
The bronchoscopic delivery of a high dose of $300 \mathrm{mg}$ surfactant $\cdot \mathrm{kg}^{-1}$ bw caused an immediate, impressive and highly-significant improvement in the arterial oxygenation, with an increase in the $\mathrm{Pa}, \mathrm{O}_{2} / \mathrm{Fi}_{1}, \mathrm{O}_{2}$ from $109 \pm 8 \mathrm{mmHg}$ before to $210 \pm 20 \mathrm{mmHg} 12 \mathrm{~h}$ after surfactant administration. In some patients who had received a radial-artery catheter for online measurement of the partial pressure of oxygen, the rise in $\mathrm{Pa}_{2} \mathrm{O}_{2}$ was already encountered during the application procedure [11]. In 25 out of the 27 patients, the oxygenation index increased by $\geqslant 25 \%$ within this time period. Detailed analysis of the alterations in gas exchange by the multiple inert-gas elimination technique, undertaken in the preceding substudy in a smaller number of patients [11], had demonstrated that the improvement in arterial oxygenation was largely attributable to a marked reduction in shunt flow, with increased appearance of areas with normal ventilation-perfusion ratios and some enhanced perfusion of regions with low ventilationperfusion ratios. These findings suggested that the predominant underlying event is the recruitment of nonaerated alveolar regions by the exogenously administered surfactant material. Such recruitment was evidently not achieved by the currently applied "mechanical" forces, as the abnormalities occurred in spite of the relatively high PEEP level of $16.3 \pm$ $2.8 \mathrm{cmH}_{2} \mathrm{O}$. It is a reasonable explanation to suggest that the surface-active material, due to its lateral spreading facilities, was also distributed to the opening of the atelectatic regions, locally reducing the pathologically high surface-tension values at these sites [14], thereby giving way to re-opening at the given level of mechanical forces.

The presently noted gas-exchange responses to the natural bovine surfactant administration are thus well in line with those usually encountered in neonatal respiratory distress syndrome (RDS), with those for calf-lung surfactant-extract administration in paediatric ARDS [13] and the response to $4 \times 100 \mathrm{mg} \cdot \mathrm{kg}^{-1} \mathrm{bw}$ Survanta instillation in adults with ARDS [17], recently being reported. They differ from the finding of limited alterations in gas exchange in response to $50 \mathrm{mg} \cdot \mathrm{kg}^{-1}$ bw of a porcine surfactant in ARDS [9], and in particular from the results with aerosolized synthetic surfactant (Exosurf) administration in septic ARDS [12]. The most reasonable explanation for these discrepancies is the difference in the total amount of surfactant being delivered to the bronchoalveolar space. In view of the dramatically increased surfactant inhibitory capacities in the lungs of ARDS patients [2, 3, 5], the "normal" neonatal dose of $50 \mathrm{mg} \cdot \mathrm{kg}^{-1}$ bw appears to be insufficient, but a higherdosage regimen is probably mandatory to overcome the inhibitory capacities in the alveolar space in severe ARDS, which is well in accordance with data from several experimental studies [18]. This view is further supported by: 1) the finding in the accompanying paper [14] that in response to the currently undertaken surfactant administration the alveolar phospholipid pool is several-fold increased above control values, but the phospholipid-protein ratio and the surfactant properties are still not fully normalized; and 2) the observation that in those patients demanding a second surfactant dosage due to loss of the initial improvement in arterial oxygenation, the higher "loading" with active surfactant material again had an effect on the rapid improvement in gas exchange. There is thus good cumulative evidence that in ARDS high quantities of surface active material are required for improvement in gas exchange, in the range 200-500 $\mathrm{mg} \cdot \mathrm{kg}^{-1} \mathrm{bw}$. Therefore, the daily dose of $\sim 5 \mathrm{mg} \cdot \mathrm{kg}^{-1}$ bw Exosurf in the study with aerosol application [12] is indeed far beyond the scope of a reasonable dosage and cannot be expected to have acute effects on gas exchange. This was all the more true as the synthetic material chosen in that study [12] was more sensitive to inhibition by plasma proteins than hydrophobic apoprotein-containing natural surfactant preparations.

The present study was limited in that it was noncontrolled, i.e. no direct comparison with a standard therapy group concerning duration of mechanical ventilation, length of stay at the intensive care unit and mortality could be undertaken. Reference to historical controls is prone to various pitfalls, and might best be performed for mortality as based on the APACHE II score. Concerning this variable, with all patients being in septic shock and acute lung injury, an overall risk of death of $74.0 \pm 3.5 \%$ was calculated [19], as compared to the actual mortality of $44.4 \%$. When analysing the differences between survivors and nonsurvivors, the severity of the initial gas-exchange abnormalities was found not to discriminate. However, those who succumbed had significantly higher APACHE II scores and a higher incidence of accompanying renal and liver failure, all pointing to the significance of sepsis for the survival rate. It is in line with this observation that none of the patients died from respiratory failure (nontreatable arterial hypoxaemia), but all who succumbed died in persistent respiratory failure, i.e. severe ARDS manifestation until death.

Drawn against this background it remains open if such transbronchial surfactant therapy might be able to affect overall mortality in septic ARDS, even when taking into account the possible role of a perpetuation of inflammatory responses by hyperoxia and/or baro/volutrauma [20-22] that might be beneficially influenced by surfactant therapy.

The ventilatory modes engaged in the present study included high PEEP levels as the conventional mechanical approach to keeping atelectatic lung areas open for reduction of shunt flow and possibly, which is still a matter of debate, for reducing baro/ volutrauma. This study did not follow the concept of low tidal-volume ventilation (actual mean tidal volume $11.0 \pm 0.5 \mathrm{~mL} \cdot \mathrm{kg}^{-1} \mathrm{bw}$ ) and permissive hypercapnia, as this concept was not approved when designing the study. Further investigations in surfactant replacement therapy should address the question whether comparably prompt improvement of arterial oxygenation may also be achieved under conditions of low tidal-volume ventilation, and whether this is accompanied by a reduction in ventilator dependency, duration at the intensive care unit and mortality rate.

To conclude, bronchoscopic administration of a large quantity of natural surfactant in patients with 
severe acute respiratory distress syndrome and septic shock was found to be feasible and safe, without untoward effects on gas exchange, lung mechanics and haemodynamics during the procedure of surfactant delivery. A highly-significant improvement in arterial oxygenation with approximate doubling of the oxygen tension in arterial blood/inspiratory oxygen fraction values was noted in response to the surfactant administration. The overall mortality of the patients was $44.4 \%$ compared to $74.0 \%$ as anticipated from the Acute Physiology and Chronic Health Evaluation II score, and none of the patients died from refractory or progressive respiratory failure. Bronchoscopic administration of a sufficient quantity of surface-active material to overcome inhibitory capacities in the alveolar compartment may offer the possibility of opening atelectatic regions, together with an improvement in gas exchange and a reduction in the "aggressiveness" of mechanical ventilation in severe acute respiratory distress syndrome.

\section{References}

1. Soll RF. Clinical trials of surfactant therapy in the newborn. In: Robertson B, Taeusch HW, eds. Surfactant Therapy for Lung Disease. New York, Marcel Dekker Inc., 1995; pp. 407-442.

2. Günther A, Siebert C, Schmidt R, et al. Surfactant alterations in severe pneumonia, ARDS and cardiogenic lung edema. Am J Resp Crit Care Med 1996; 153: $176-184$.

3. Gregory TJ, Longmore WJ, Moxley MA, et al. Surfactant chemical composition and biophysical activity in acute respiratory distress syndrome. J Clin Invest 1991; 88: 1976-1981.

4. Hallman M, Spragg R, Harrell JH, Moser M, Gluck L. Evidence of lung surfactant abnormality in respiratory failure. Study of bronchoalveolar lavage phospholipids, surface activity, phospholipase activity, and plasma myoinositol. J Clin Invest 1982; 70 : 673-683.

5. Pison U, Seeger W, Buchhorn R, et al. Surfactant abnormalities in patients with respiratory failure after multiple trauma. Am Rev Respir Dis 1989; 140: 10331039.

6. Schmidt R, Meier U, Yabut-Perez M, et al. Alteration of fatty acid profiles in different pulmonary surfactant phospholipids in acute respiratory distress syndrome and pneumonia. Am J Respir Crit Care Med 2001; 163: 95-100.

7. Seeger W, Günther A, Walmrath HD, Grimminger F, Lasch HG. Alveolar surfactant and adult respiratory distress syndrome. Pathogenetic role and therapeutic prospects. Clin Investig 1993; 71: 177-190.

8. Lewis JF, Jobe AH. Surfactant and the adult respiratory distress syndrome. Am Rev Respir Dis 1993; 147: 218-233.

9. Spragg RG, Gilliard N, Richmann P, et al. Acute effects of a single dose of porcine surfactant on patients with the adult respiratory distress syndrome. Chest 1994; 105: 195-202.

10. Gregory TJ, Steinberg KP, Spragg R, et al. Bovine surfactant therapy for patients with acute respiratory distress syndrome. Am J Respir Crit Care Med 1997; 155: 1309-1315.

11. Walmrath D, Günther A, Ghofrani HA, et al. Bronchoscopic surfactant administration in patients with severe adult respiratory distress syndrome and sepsis. Am J Respir Crit Care Med 1996; 154: 57-62.

12. Anzueto A, Baughman R, Guntupalli $\mathrm{KK}$, et al. Aerosolized surfactant in adults with sepsis-induced acute respiratory distress syndrome. $N$ Engl $\mathrm{J} \mathrm{Med}$ 1996; 334: 1417-1421.

13. Willson DE, Zaritsky A, Bauman LA, et al. Instillation of calf lung surfactant extract (Calfactant) is beneficial in pediatric acute hypoxemic respiratory failure. Members of the Mid-Atlantic Pediatric Critical Care Network. Crit Care Med 1999; 27: 188-195.

14. Günther A, Schmidt R, Harodt J, et al. Bronchoscopic administration of bovine natural surfactant in ARDS and septic shock: impact on biophysical and biochemical surfactant properties. Eur Respir J 2002; 19: 797-804.

15. Murray JF, Matthay MA, Luce JM, Flick MR. An expanded definition of the adult respiratory distress syndrome. Am Rev Respir Dis 1988; 138: 720-723.

16. Bone RC, Fisher CJ, Clemmer TP, Slotman GJ, Metz CA, Balk RA. Sepsis syndrome: a valid clinical entity. Crit Care Med 1989; 17: 389-393.

17. Gregory TJ, Gadek JE, Weiland JE, et al. Survanta $\mathbb{R}$ supplementation in patients with acute respiratory distress syndrome (ARDS). Am J Respir Crit Care Med 1994; 49: A125.

18. Günther A, Seeger W. Resistance to surfactant inactivation. In: Robertson B, Taeusch HW, eds. Surfactant Therapy for Lung Disease. New York, Marcel Dekker, 1995; 269-292.

19. Knaus WA, Sun X, Hakim RB, Wagner DP. Evaluation of definitions for adult respiratory distress syndrome. Am J Respir Crit Care Med 1994; 150: 311-317.

20. Tremblay LN, Valenza F, Ribeiro SP, Li J, Slutsky AS. Injurious ventilatory strategies increase cytokines and $\mathrm{c}$-fos m-RNA expression in an isolated rat lung model. J Clin Invest 1997; 99: 944-952.

21. Von Bethmann AN, Brasch R, Nusing R, et al. Hyperventilation induces release of cytokines from perfused mouse lung. Am J Respir Crit Care Med 1998; 157: 263-272.

22. Ghofrani HA, Rosseau S, Walmrath $\mathrm{D}$, et al. Compartimentalized lung cytokine release in response to intravascular and alveolar endotoxin challenge. $\mathrm{Am}$ J Physiol 1996; 270: L62-L68. 